\title{
Chicks of the Great Spotted Cuckoo May Turn Brood Parasitism into Mutualism by Producing a Foul-Smelling Secretion that Repels Predators
}

\author{
Gregory Röder • Daniela Canestrari • Diana Bolopo • \\ José M. Marcos • Neil Villard • Vittorio Baglione • \\ Ted C. J. Turlings
}

Received: 7 March 2014 /Revised: 19 March 2014 / Accepted: 21 March 2014 /Published online: 24 April 2014

(C) Springer Science+Business Media New York 2014

\begin{abstract}
The great spotted cuckoo (Clamator glandarius) is an important brood parasite of carrion crows (Corvus corone corone) in northern Spain. We recently found that, unlike what is commonly known for cuckoo-host interactions, the great spotted cuckoo has no negative impact on average crow fitness in this region. The explanation for this surprising effect is a repulsive secretion that the cuckoo chicks produce when they are harassed and that may protect the brood against predation. Here, we provide details on the chemical composition of the cuckoo secretion, as well as conclusive evidence that the dominating volatile chemicals in the secretion are highly repellent to model species representative of common predators of the crows. These results support the notion that, in this particular system, the production of a repulsive secretion by the cuckoo chicks has turned a normally parasitic interaction into a mutualistic one.
\end{abstract}

Electronic supplementary material The online version of this article (doi:10.1007/s10886-014-0426-0) contains supplementary material, which is available to authorized users.

G. Röder $\cdot$ N. Villard $\cdot$ T. C. J. Turlings $(\bowtie)$

Laboratory of Fundamental and Applied Research in Chemical Ecology (FARCE), Institute of Biology, University of Neuchâtel, Rue Emile-Argand 11, 2000 Neuchâtel, Switzerland

e-mail: ted.turlings@unine.ch

D. Canestrari

Department of Biology of Organisms and Systems (BOS), University of Oviedo, Oviedo, Asturias, Spain

D. Canestrari

Research Unit of Biodiversity (UMIB, CSIC, UO), Oviedo, Spain

D. Bolopo $\cdot$ J. M. Marcos $\cdot$ V. Baglione

Department of Agro-forestry, University of Valladolid, Valladolid, Spain

\section{Baglione}

Sustainable Forest Management Research Institute, Palencia, Spain
Keywords Great spotted cuckoo · Clamatorglandarius . Carrion crows · Corvus corone corone · Repellency · Predators $\cdot$ Brood parasitism $\cdot$ Mutualism

\section{Introduction}

Various species of cuckoos (family Cuculidae) typically lay their eggs in the nests of other bird species and rely on the host pair to raise their chicks. In most cases, the fitness of the adoptive parents is greatly reduced as a result of the presence of the cuckoos. Evicting cuckoos annihilate host reproductive success by tossing out their eggs or chicks. Conversely, non-evicting cuckoos are raised alongside host brood, but often harm the hosts nonetheless, by outcompeting their offspring for food (Rothstein 1990; Winfree 1999). The evolutionary arm race between brood parasites and their hosts is central in evolutionary biology (Kilner and Langmore 2011; Krüger 2007).

We recently found that, in at least one case, the presence of a cuckoo chick may in fact be neutral or even beneficial to the fitness of the hosts, depending on seasonal predator pressures (Canestrari et al. 2014). In our study area in the north of Spain, the great spotted cuckoo frequently had a positive impact on breeding success of its host, the carrion crow. This surprising effect is explained by a malodorous secretion that juvenile cuckoos produce upon harassment. The secretion is repellent to various predators and, indeed, during years of high predator pressure the nests with cuckoo chicks are more successful in completing the reproductive attempt (i.e., at least one crow fledging produced) than nests without cuckoos. Despite the fact that such successful nests produced fewer crow fledglings than successful nests without a cuckoo, the overall outcome of the cuckoo-crow interaction results in an average net crow fitness benefit for parasitized nests (Canestrari et al. 2014). 
To obtain information on the chemical composition of the cuckoo excretion and to determine if the compounds comprised are indeed repellent to predators we carried out a series of chemical analyses of the excretions to identify the dominant volatile compounds. To confirm the repellent effect of these compounds, we generated a pure synthetic secretion, and tested this artificial secretion on captive and semi-captive of nest predators.

\section{Methods and Material}

Chemical Analyses and Identification At the study site in northern Spain $\left(42^{\circ} 37^{\prime} \mathrm{N}, 5^{\circ} 26^{\prime} \mathrm{W}\right)$, we selected five nests that hosted a 4-10 days-old chick of the great spotted cuckoo. Excretions from the five chicks were obtained by temporarily removing them by hand from their nests and then placing a glass vial near their cloaca. Without further harassment they would readily expel the secretion, of which we collected up to $1.2 \mathrm{ml}$ into the vial. The samples were kept in glass vials or Eppendorfs and stored at $-20^{\circ} \mathrm{C}$ until they were shipped to the Neuchâtel lab. All but one sample were kept on dry-ice during the shipment and upon arrival they were stored at $-80^{\circ} \mathrm{C}$ until they were used for the chemical analyses.

Volatiles collected from each of the five bird secretions were analyzed using gas chromatography and mass spectrometry (GC/MS). Volatile compounds were trapped with the use of four different headspace techniques using a multipurpose sampling system (MPS2, Gerstel GmBH, Mellinghofen, Germany), including solid-phase microextraction (SPME), microvial headspace trapping, stir bar sorptive extraction (SBSE), and dynamic headspace (DHS). To be exhaustive and to exploit the full potential of each technique, each sample was prepared and extracted using multiple parameters (incubation, agitation, duration, adsorbent, temperature, flow, etc.). In total, 76 analyses were carried out to assess the presence of volatile components (Canestrari et al., 2014). Here, we present further details on these analyses that were done with the solidphase microextraction (SPME) fibers. The reason for the choice of the SPME analyses was that they provided the cleanest results with the consistent presence of each of the dominating compounds. We realize that the SPME technique provides poor quantitative information, but this is not relevant to the aim of this study, i.e., the demonstration that the detected volatile compounds repel predators.

All analyses were done with gas chromatographs (GC; HP 6890 or Agilent 7890A) coupled to Agilent mass spectrometer detectors (MS; 5973 or 5975C). Samples were prepared and introduced into the GC with the use of the multipurpose sampling systems. Compounds were separated on Agilent HP-1MS columns $(30 \mathrm{~m}$ length $\times 0.25 \mathrm{~mm}$ i.d., and $0.25 \mu \mathrm{m}$ film thickness). In all cases, the MSD transfer line temperature was set at $280{ }^{\circ} \mathrm{C}$, and the ion source and quadrupole temperatures were set at 230 and $150{ }^{\circ} \mathrm{C}$, respectively. Electron impact (EI) mode was used with a scanning over the mass range of $30-350$.

For SPME sampling, about $0.1 \mathrm{ml}$ of each excretion was incubated in a $20 \mathrm{ml}$ vial for $5 \mathrm{~min}$ at $35^{\circ} \mathrm{C}$ before inserting a $100 \mu \mathrm{m}$ polydimethylsiloxane (PDMS) coated fiber (Supelco) into the headspace during $20 \mathrm{~min}$. Afterward, compounds were thermally desorbed from the fiber during $3 \mathrm{~min}$ (splitless mode, $250{ }^{\circ} \mathrm{C}, 6.22 \mathrm{psi}$ pressure, $200.5 \mathrm{ml} / \mathrm{min}$ purge flow, helium carrier gas) before injection onto the GC column. The initial column temperature of $40{ }^{\circ} \mathrm{C}$ was held for $1 \mathrm{~min}$, then was ramped $10{ }^{\circ} \mathrm{C} / \mathrm{min}$ until $180{ }^{\circ} \mathrm{C}$ (hold time $5 \mathrm{~min}$ ), followed by a second ramp of $10^{\circ} \mathrm{C} / \mathrm{min}$ until $220^{\circ} \mathrm{C}$ (hold time $5 \mathrm{~min}$ ), and finally a $3 \mathrm{~min}$ post run at $250^{\circ} \mathrm{C}$. The helium flow rate was $0.9 \mathrm{ml} / \mathrm{min}$ (constant flow mode).

Corresponding control analyses with empty vials were carried out in order to determine which of the compounds were not of cuckoo origin. These air contaminants, plasticizers, etc. were excluded from the analyses. In addition, a blank analysis was conducted between each real sample in order to purge the system.

Among the different secretions collected from five cuckoos, some compounds were detectable only for one sample. Exact identification was pursued only for the $22 \mathrm{com}$ pounds that were consistently detected and present in at least three of the five excretion samples. In order to confirm the identities of these main compounds, we analyzed pure standards (Sigma-Aldrich \& Fluka) for each of them. Confirmations were obtained by comparisons of retention times as well as mass spectra.

Synthetic Blend of Juvenile Cuckoo Secretions Twenty-two pure standards of the dominating volatile compounds were mixed together in order to produce an artificial solution that mimicked the odor of juvenile cuckoo's secretion (Fig. 1). The ratios in this mixture were based on the results for the four samples that had been kept frozen until the analysis; the sample that was transported under ambient temperature had degraded and showed a very different profile. The components were carefully dispensed in a $10 \mathrm{ml}$ glass vial, while respecting their average relative proportions as detected in the multiple analysis of natural secretion of cuckoo. These proportions fell well within the variable range that we observed in the samples (Fig. 2a and b). The mixture was stored at $5{ }^{\circ} \mathrm{C}$ in $7 \mathrm{ml}$ amber vials before use in repellence tests. For feeding assays that were conducted with captive animals, we sprayed 5-10 $\mu$ l of this synthetic mix on pieces of chicken of approximately $3-5 \mathrm{~g}$.

Repellent Effects of the Artificial Secretion on Predators The synthetic mixture was tested in two choices feeding assays similar to the ones in Canestrari et al. (2014). In this previous study, we tested and demonstrated the repulsive effect of the 


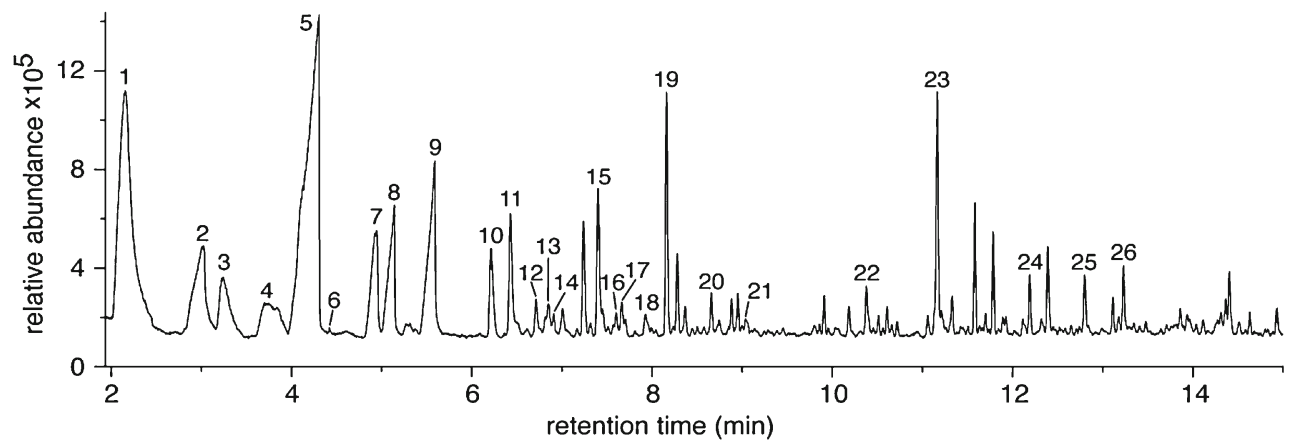

Fig. 1 Representative chromatogram of the volatiles emitted from defensive excretion of the juvenile great spotted cuckoo. The volatiles were analyzed by various methods, as described in the text. This particular chromatogram was obtained by SPME method. It includes dominant compounds: 1, acetic acid; 2, propanoic acid; 3, dimethyl disulfide; 4, isobutyric acid; 5 , butyric acid; 6 , pivalic acid; 7 , isovaleric acid; 8,2 -

natural cuckoo secretions on potential nest predators. Here, we applied the synthetic mix in a similar way. All experiments were conducted at our research facilities in Spain, and they were authorized by Junta de Castilla y León. Pieces of chicken meat were sprayed with the transparent synthetic mixture and offered to seven hand-raised raptors (i.e., four peregrine methylbutanoic acid; 9 , valeric acid; 10, $\alpha$-pinene; 11, dimethyl trisulfide; 12 , phenol; 13 , $\beta$-pinene; 14 , caproic acid; 15,3 -carene; 16, 2 ethylhexanol; 17, limonene; 18, acetophenone; 19, p-cresol; 20, nonanal; 21, camphor; 22, dimethyl tetrasulfide, 23, indole; 24 , skatole; 25 , longicyclene; 26 , longifolene

falcons Falco peregrinus, one gyrfalcon Falco rusticolus, one gyrfalcon $\times$ peregrine falcon hybrid and one gyrfalcon $\times$ saker falcon Falco cherrug hybrid; all birds had been legally bred for use in falconry), six captive carrion crows (intraspecific predation is common in this species), and 15 quasi feral cats that normally hunt in the vicinity of the experimental site,
Fig. 2 Comparative illustrations showing the proportional representation of the 22 dominant volatiles detected from the natural secretions of juvenile cuckoos and the composition of the synthetic blend. A) Average abundances of corresponding components in natural secretions are presented in percents \pm standard errors. Because overall emissions from the excretions varied strongly in quantity, data were weighted in function of the total production of compounds in each sample $(N=4)$. B) The relative quantities in which the different compounds were mixed in order to obtain a solution mimicking the repellant odors released by great spotted cuckoo chicks. Chemicals are listed in order of their appearance in the analysis (retention time)

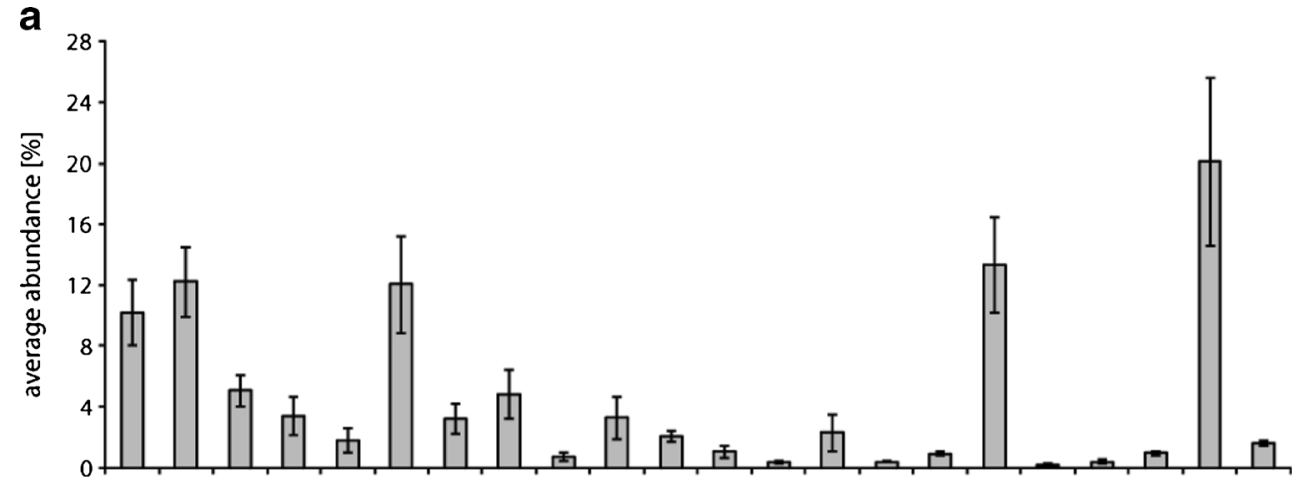

b

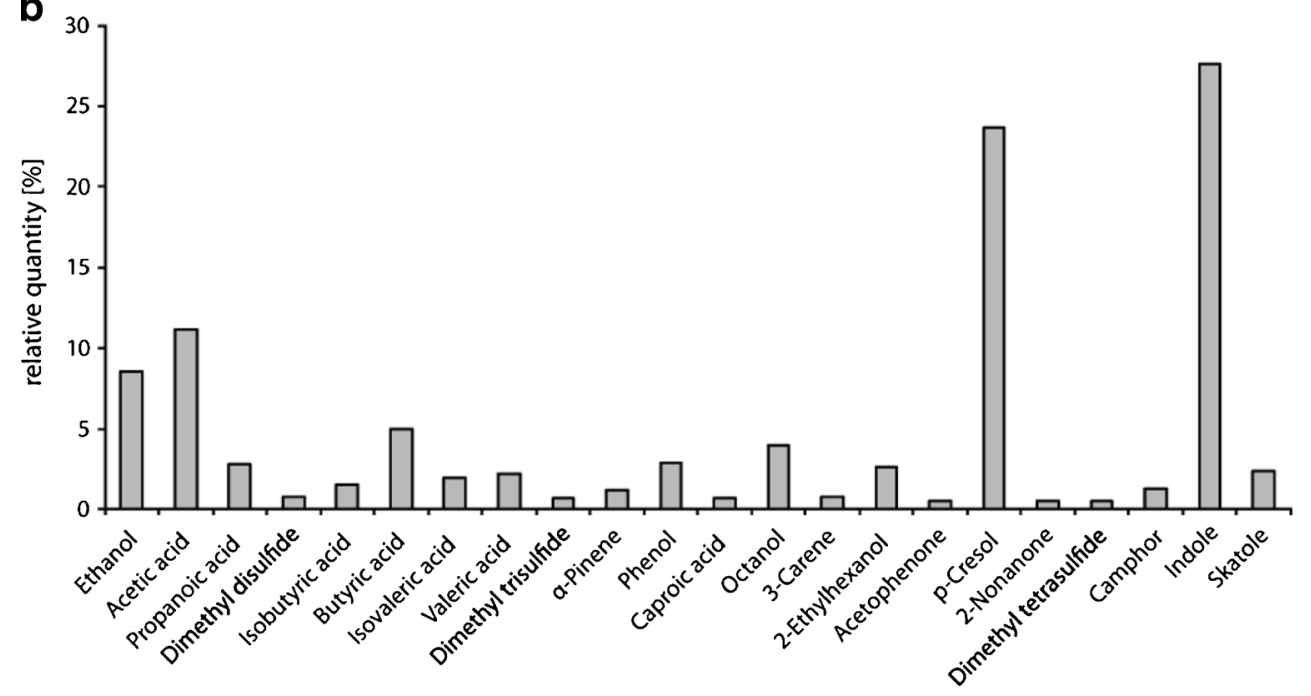


but are tolerant enough of humans to be attracted with food (Canestrari et al., 2014). The repellence tests were adapted to each model species. Cats were offered a cardboard tray with 10 pieces of chicken meat (approx. $5 \mathrm{~g}$ each). The ten pieces were sprayed either with the natural secretion (results presented in Canestrari et al. 2014), with the synthetic blend, or with tap water. We recorded the acceptance of the baits. Conservatively, we considered that an individual cat accepted the bait if it took a bite out of at least one piece of the offered meat.

Crows were offered six pieces of meat, one at a time for one min, alternating treated $(N=3)$ and control meat $(N=3)$. We put the bait on a perch of the aviary compartment where the focal birds had been isolated. We observed the response of the bird after it discovered the bait. We considered that the meat was 1) consumed, if the crow ate it all or part of it, or if it cached it; 2) rejected, if the bird did not touch it or drop it immediately after it was taken in the beak. After each presentation, the leftover bait was removed. We intended to follow the same procedure with falcons, but their strong reaction to the first presentation of treated meat made them unwilling to accept any more food, regardless of whether treated or not. For each bird, we can, therefore, only report on the first presentation of the treated meat. The Fisher Exact Test and the binomial test were used to analyze the cat data and the falcon data, respectively, whereas a Generalized Linear Mixed Model was run for crow data, using a dichotomous response variable (eaten/refused), treatment and order of presentation as explanatory variables and bird identity as random term.

\section{Results}

Chemical Analyses Overall, more than 60 volatiles were detected in the different secretions collected from five cuckoos. The 22 compounds that were present in at least three samples were considered as the most relevant ones and used for further evaluations. Analyses of purchased standards showed that in all cases the tentative identifications were found to be correct. Figure 1 shows a typical chromatogram obtained with the SPME method that contains most of these major odorous compounds.

Synthetic Blend of Juvenile Cuckoo Secretion The synthetic mixture was a fully transparent solution that had neither the consistency, nor the color of the natural secretion. This allowed us to specifically assess the attractiveness or repulsiveness of the pungent odor, and it assured that there were no visual effects.

Repellent Effects of the Artificial Secretion on Predators Cats showed the same aversive reaction towards the synthetic blend as we previously reported for the natural secretion
(Canestrari et al. 2014). None of the six cats that were offered the treated meat touched it, whereas eight of nine cats ate all ten pieces of control meat (Fisher Exact Test, $P=0.014$ ). Falcons also strongly avoided the synthetic blend and refused to eat the treated meat at the first presentation (binomial test, $P=0.008, N=7)$. In contrast, crows consumed the same proportion of treated and control meat $(44 \% ; Z=0.312$, $P=0.755)$.

\section{Discussion}

Brood parasitizing cuckoos are notorious for the harm they cause to the offspring of their host parents. They can break or toss out the eggs of the hosts, or they remove or cause starvation of the host nestlings (Rothstein, 1990). Many but not all host species have evolved defenses against the brood parasites (Kilner and Langmore 2011). For the species that do not exhibit any defense (Krüger 2011), this has been explained by relatively recent host/parasite contact or by hosts refraining to exhibit their defensive repertoire when costs outweigh the benefits (Spottiswoode et al. 2012).

We showed that the interaction between the great spotted cuckoo and carrion crow can be mutualistic in seasons with high predator pressure (Canestrari et al. 2014). We proposed that the reason for this is a secretion that the cuckoo chicks eject upon harassment, protecting the brood against predators. Here, we confirm with a synthetic mimic of the secretion that the awful smell of the caustic acids, indoles, phenols, and sulfuric compounds (Fig. 1) indeed deters mammalian predators and raptor birds. Interestingly, crows do not seem to avoid the synthetic blend (this study), although they showed strong avoidance of the natural secretion (Canestrari et al. 2014). Possibly the observed rejection of the natural secretion by the crows is based on visual cues (the natural secretion is pitch-black), or on the combination of visual and olfactory cues. A non-repellent effect on crows of the secretion odor can be expected for carrion feeders, and ensures that adoptive crow parents continue to provision a nest after a cuckoo chick produces the secretion.

A published survey among ornithologists suggests that avian chemical defenses against predators may be common (Weldon and Rappole 1997). As yet, chemical defenses in birds have been poorly studied, with some exceptions. For instance, aposematically colored birds of the genus Pitohui produce toxic steroidal alkaloids called batrachotoxinins (Dumbacher et al. 1992). Reports on the repellent odors have been largely anecdotal except for hoopoes (Rajchard 2010; Martin-Vivaldi et al. 2010), whose malodorous nests are also assumed to repel predators. Fulmars, a group of seabirds related to albatrosses, are known to use an active chemical defense against intruders. Their chicks "spit" stomach oil at 
anything approaching them (Warham 1990). In addition to the stickiness of the oil, its fishy odor may contribute to the defensive function. Recently, Parejo et al. (2013) proposed that the orange liquid that nestlings of the insectivorous Eurasian roller (Coracias garrulus) expel (vomit) might function to deter predators. The liquid contains insect-derived acids and was shown to deter dogs from eating meat.

The current study is to our knowledge the first to identify avian-produced volatiles and confirm their repellent effect on predators. Although most of the compounds we identified have a repugnant smell at the doses emitted by the cuckoo, it remains to be determined which ones are the most effective at repelling predators. The acids and the sulfides are top candidates and indeed there is evidence that short fatty acids repel coyotes and dogs (Lehner et al. 1976) and dimethyl trisulfide has been shown to repel wolverines (Landa and Tømmerås 1997).

The biochemical source of the substances also remains unknown. The identified compounds are commonly associated with rotting substrates such as carcasses and excrement (Dekeirsschieter et al. 2009). Therefore, a bacterial origin is one logical option. In hoopoes the bacterium Enterococcus faecalis present in their uropygial gland has been implicated in the production of the malodor, as well as the production of peptides with antibacterial properties (Martin-Vivaldi et al. 2010). Whether this bacterial origin and a possible anti-pathogen function also applies to the cuckoo excretions remains to be determined. Given that the secretion is expelled only upon harassment, an antimicrobial function seems unlikely.

We conclude that the excretion produced by chicks of the great spotted cuckoo is highly repellent to potential predators. This explains why, during years with high predator pressures, nests of the carrion crow have on average a higher success rate when they carry a cuckoo chick than nests without a cuckoo (Canestrari et al. 2014). With this effective chemical defense the cuckoos have changed a normally parasitic interaction into a potentially mutualistic interaction.

\section{References}

Canestrari D, Bolopo D, Turlings TCJ, Röder G, Marcos JM, Baglione V (2014) From parasitism to mutualism: unexpected interactions between a cuckoo and its host. Science 343:1350-1352

Dekeirsschieter J, Verheggen F, Gohy M, Hubrecht F, Bourguignon L, Lognay G, Haubruge E (2009) Cadaveric volatile organic compounds released by decaying pig carcases (Sus domesticus L.) in different biotopes. Forensic Sci Int 189:46-53

Dumbacher JP, Beehler BM, Spande TF, Garraffo HM, Daly JW (1992) Homobatrachotoxin in the genus Pitohui: chemical defense in birds? Science 258:799-801

Kilner RM, Langmore NE (2011) Cuckoos versus hosts in insects and birds: adaptations, counter-adaptations and outcomes. Biol Rev 86: $836-852$

Krüger O (2007) Cuckoos, cowbirds and hosts: adaptations, trade-offs and constraints. Phil Trans R Soc B 362:1873-1886

Krüger O (2011) Brood parasitism selects for no defence in a cuckoo host. Proc R Soc Lond B 278:2777-2783

Landa A, Tømmerås BA (1997) A test of aversive agents on wolverines. J Wildl Manag 61:510-516

Lehner PN, Krumm R, Cringan AT (1976) Tests for olfactory repellents for coyotes and dogs. J Wildl Manag 40:145-150

Martin-Vivaldi M, Peña A, Peralta-Sanchez JM, Sánchez L, Ananou S, Ruiz-Rodriguez M, Soler JJ (2010) Antimicrobial chemicals in hoopoe preen secretions are produced by symbiotic bacteria. Proc R Soc Lond B 277:123-130

Parejo D, Avilés JM, Peña A, Sánchez L, Ruano F, Zamora-Muñoz C, Martín-Vivaldi M (2013) Armed rollers: does nestling's vomit function as a defence against predators? PLoS One 8:e68862. doi:10.1371/journal.pone.0068862

Rajchard J (2010) Biologically active substances of bird skin: a review. Vet Med 55:413-421

Rothstein SI (1990) A model system for coevolution—avian brood parasitism. Annu Rev Ecol Syst 21:481-508

Spottiswoode C, Kilner R, Davies NB (2012) Brood parasitism. In: Royle NJ, Smiseth PT, Kölliker M (eds) The evolution of parental care. Oxford University Press, Oxford, pp pp 226-356

Warham J (1990) The petrels: their ecology and breeding systems. Academic, London, p 440

Weldon PJ, Rappole JH (1997) A survey of birds odorous or unpalatable to humans: possible indications of chemical defense. J Chem Ecol 23:2609-2633

Winfree R (1999) Cuckoos, cowbirds and the persistence of brood parasitism. Trends Ecol Evol 14:338-343 